\title{
Lipid and fatty acid profiles of migrating Southern Hemisphere humpback whales Megaptera novaeangliae
}

\author{
Courtney A. Waugh ${ }^{1, *}$, Peter D. Nichols ${ }^{2}$, Michael C. Noad ${ }^{3}$, Susan Bengtson Nash ${ }^{4}$ \\ ${ }^{1}$ National Research Centre for Environmental Toxicology (Entox), The University of Queensland, Brisbane, Queensland 4108, \\ Australia \\ ${ }^{2}$ CSIRO Marine and Atmospheric Research, Wealth from Oceans Flagship, GPO Box 1538, Hobart, Tasmania 7000, Australia \\ ${ }^{3}$ Cetacean Ecology and Acoustics Lab (CEAL), School of Veterinary Science, The University of Queensland, Gatton, \\ Queensland 4343, Australia \\ ${ }^{4}$ Atmospheric Environment Research Centre (AERC), Griffith University, Nathan, Queensland 4111, Australia
}

\begin{abstract}
The lipid and fatty acid (FA) composition of the outer blubber layer was characterized in 46 east Australian migrating humpback whales Megaptera novaeangliae. Samples were obtained at 2 time points of the annual migration, which occurs between Antarctic feeding grounds and low-latitude breeding grounds and is associated with a prolonged period of fasting. Blubber lipid composition was dominated by triacylglycerols in all individuals, and the FA profiles of both migration cohorts and sexes were dominated by monounsaturated fatty acids (MUFA). Results indicate that males primarily mobilise polyunsaturated fatty acids in response to migration and fasting, favouring the most readily utilisable FA as governed by their physicochemical properties. In comparison, females appear to initially mobilise short-chain ( $<18$ carbons) MUFA stores, potentially to attend to dependent calves' thermoregulatory needs. Feeding ecology investigations suggested that humpback whales have a species-specific FA composition of their blubber, including a detectable influence of their diet. This study provides the first insight into lipid and FA profiles of Southern Hemisphere humpback whales. A comprehensive understanding of FA dynamics, especially during times of energy deficit, is essential for understanding the nutritional status of Southern Hemisphere humpback whales and thereby the risks posed by growing environmental threats including toxic and persistent lipophilic pollutants.
\end{abstract}

KEY WORDS: Humpback whale $\cdot$ Megaptera novaeangliae $\cdot$ Biopsy sampling $\cdot$ Blubber $\cdot$ Fatty acid Resale or republication not permitted without written consent of the publisher

\section{INTRODUCTION}

Lipids play a fundamental role in many biological, physiological, and metabolic processes. Fatty acids (FA) constitute the largest component of neutral lipids, such as triacylglycerols (TAG), wax esters, and polar phospholipids (Tollit et al. 2010). TAG embody the most common form of storage lipids and are the predominant lipid class found in marine mammal blubber (Budge et al. 2006). FA profiling of marine mammal blubber can provide valuable information regarding species ecology, such as foraging patterns and trophic interactions, which in turn may serve to differentiate populations and subpopulations (Kakela \& Hyvarinen 1996, Iverson et al. 2002, Best et al. 2003, Thiemann et al. 2009). FA profiles can also provide information regarding prey composition and an individual's diet over periods of weeks to months. By comparison, the commonly applied approach of stomach content analysis provides a specific, albeit often biased, snapshot of only the most recent intake (Iverson et al. 2004, Thiemann et al. 2009). FA pro- 
files can provide further information regarding thermoregulatory and insulating properties of the tissue as well as complement toxicokinetic investigations of lipophilic pollutants, the movement of which are governed by lipid dynamics (Strandberg et al. 2008, 2011). Most recently, FA regression models have been employed as a novel non-lethal method of age estimation in certain populations of large biopsied cetaceans (Herman et al. 2008, 2009).

Marine mammal blubber is dynamic in nature and significantly influenced by nutritional condition (Budge et al. 2006). In times of low food availability, animals mobilise stored blubber FA to provide metabolic fuel. Conversely, animals deposit FA when energy intake exceeds demands. FA metabolism at times of energy deficit is not well understood in marine mammals, especially in large baleen whales, although there is evidence to suggest that in some species it is a selective and/or temporal process (Raclot 2003, Wheatley et al. 2008). To better understand the lipid dynamics of Southern Hemisphere humpback whales Megaptera novaeangliae, we focused this study on the east Australian migrating population (E1, as designated by the International Whaling Commission, 1999).

Southern Hemisphere humpback whales have adapted to the productivity extremes of high-latitude environments. Summer feeding in the Southern Ocean supports a migration journey of up to $7 \mathrm{mo}$, to and from equatorial breeding grounds, covering a distance of $\sim 10000 \mathrm{~km}$ (Zerbini et al. 2006). This is the longest migration journey known in any mammal (Zerbini et al. 2006, Rasmussen et al. 2007) and is considerably extended in Southern Hemisphere, compared to Northern Hemisphere populations (Rasmussen et al. 2007, Stevick et al. 2011). The migration journey is associated with simultaneous fasting; energetically demanding competitive breeding behaviour in males; and gestation, parturition, and lactation in females. Individuals have been estimated to lose between one-third and one-half of their body mass over the course of the migration event (Slijper 1962, Dawbin 1966, Lockyer 1981, Baraff et al. 1991, Costa 2008). The nutritional extremes experienced by migrating humpback whales are likely to be reflected in the lipid and FA composition of blubber energy stores. Understanding the mobilisation of FA during times of increased metabolic demands, such as fasting, is essential for a detailed assessment of the increased environmental risk posed by mobilisation of co-entrained lipophilic organic pollutants. Once these pollutants are mobilised into the bloodstream, they have a heightened potential of reaching target sites of toxicity and causing adverse health effects (Bigsby et al. 1997, Imbeault et al. 2001, Martineau et al. 2002, Yordy et al. 2010).

Analysis of FA profiles in Southern Hemisphere humpback whales is also important from an ecosystem management perspective to allow an understanding of Southern Ocean trophic interactions. Little is known about the specific foraging behaviour and prey preference of Southern Hemisphere humpback whales, but it is generally accepted that these populations feed almost exclusively on Antarctic krill Euphausia superba (Chittleborough 1965, Bannister \& Hedley 2001, Paterson et al. 2001). Antarctic krill is a keystone species in the Southern Ocean ecosystem and acts as a major link between the primary producers and higher predators (O'Brien et al. 2011). Contrastingly, in the Northern Hemisphere, humpback whale populations rely on a more generalist diet, including species of fish. A previous study reported on the blubber FA profiles of humpback whales from a population in the Northern Hemisphere (Borobia et al. 1995). If blubber FA were to be determined strongly by diet, more so than by species-specific metabolism, then the FA profile of Northern Hemisphere populations of humpback whales is unlikely to be representative of the Southern Hemisphere populations (Nemoto 1959, Borobia et al. 1995, Witteveen et al. 2011). Comparisons of FA profiles between humpback whales from the Northern and Southern hemispheres, and potential prey species, may provide additional insight regarding these trophic interactions (Dalsgaard et al. 2003, Iverson et al. 2004, Budge et al. 2008).

This study is the first to describe blubber lipid and FA profiles of a Southern Hemisphere population of humpback whales. The ecological and biochemical influencing factors behind fluctuating lipid profiles are discussed, and dietary analysis is performed.

\section{MATERIALS AND METHODS}

\section{Sample collection}

Forty-six skin and blubber biopsies were obtained from free-swimming ('biopsied') humpback whales ( $\mathrm{n}=29$ males, $\mathrm{n}=17$ females; Table 1 ).

Standard blubber biopsies were collected from free-swimming individuals between 2008 and 2009 off North Stradbroke Island, southeastern Queensland, Australia (approximately $27^{\circ} 26^{\prime} \mathrm{S}, 153^{\circ} 34^{\prime} \mathrm{E}$ ). Biopsies were collected at 2 time points during the annual migration and are categorized into 2 cohorts: 
Table 1. Megaptera novaeangliae. Average blubber fatty acid (FA) composition (as percent of total FA) of 46 east Australian humpback whales. Values are given for 20 FA ( $\geq 0.05 \%)$ as the average composition of respective cohorts ( $\% \mathrm{FA} \pm \mathrm{SE}$ ). Asterisks denote significant difference between $(*)$ early vs. late migration cohorts in either male or female adults; and (**) late migration males vs. late migrating females. SFA, saturated fatty acids; MUFA, monounsaturated fatty acids; PUFA, polyunsaturated fatty acids

\begin{tabular}{|c|c|c|c|c|c|}
\hline \multirow[t]{3}{*}{ FA } & \multicolumn{2}{|c|}{ Male - } & \multicolumn{2}{|r|}{ Female } & \multirow{3}{*}{$\begin{array}{l}\text { Calf } \\
\text { Late migration } \\
(\mathrm{n}=2)\end{array}$} \\
\hline & & $-\mathrm{Ac}$ & dult & & \\
\hline & $\begin{array}{l}\text { Early migration } \\
\qquad(\mathrm{n}=17)\end{array}$ & $\begin{array}{l}\text { Late migration } \\
\qquad(\mathrm{n}=12)\end{array}$ & $\begin{array}{l}\text { Early migration } \\
\qquad(\mathrm{n}=7)\end{array}$ & $\begin{array}{l}\text { Late migration } \\
\qquad(\mathrm{n}=8)\end{array}$ & \\
\hline \multicolumn{6}{|l|}{ SFA } \\
\hline $14: 0$ & $5.8 \pm 0.4$ & $5.2 \pm 0.6$ & $6 \pm 0.7$ & $4.6 \pm 0.5$ & $4.5 \pm 0.2$ \\
\hline $16: 0$ & $11.5 \pm 0.3$ & $11.0 \pm 0.8$ & $11 \pm 1.0$ & $11.9 \pm 0.5$ & $12.9 \pm 0.8$ \\
\hline $18: 0$ & $2.2 \pm 0.2$ & $2.0 \pm 0.2$ & $2.2 \pm 0.2$ & $2.4 \pm 0.2$ & $2.3 \pm 0.1$ \\
\hline $20: 0$ & $0.4 \pm 0.2$ & $4.8 \pm 1.7$ & $0.1 \pm 0$ & $3.1 \pm 1.3$ & $4.9 \pm 4.7$ \\
\hline Total & $20 \pm 0.4$ & $22.9 \pm 2.0$ & $19.4 \pm 1.6$ & $22 \pm 1.6$ & $24.6 \pm 5.4$ \\
\hline \multicolumn{6}{|l|}{ MUFA } \\
\hline $14: 1 \omega 5 c$ & $1.2 \pm 0.1$ & $1.4 \pm 0.4$ & $1.5 \pm 0.2$ & $0.8 \pm 0.1$ & $0.4 \pm 0.2$ \\
\hline $16: 1 \omega 7 \mathrm{C}$ & $14.6 \pm 0.6$ & $13.6 \pm 1.4$ & $17.5 \pm 0.7$ & $12.8 \pm 0.9$ & $14.4 \pm 3.3$ \\
\hline $17: 1 \omega 8 \mathrm{c}^{\mathrm{a}}$ & $0.5 \pm 0.0$ & $0.4 \pm 0$ & $0.5 \pm 0$ & $0.4 \pm 0$ & $0.4 \pm 0.1$ \\
\hline $18: 1 \omega 9 \mathrm{c}$ & $23.2 \pm 0.5$ & $25.1 \pm 1$ & $23.2 \pm 0.9$ & $22 \pm 0.9$ & $20.6 \pm 3$ \\
\hline $18: 1 \omega 7 \mathrm{C}$ & $8.8 \pm 0.2$ & $9.4 \pm 0.3$ & $8.8 \pm 0.3$ & $8.2 \pm 0.2$ & $8.1 \pm 0.3$ \\
\hline $20: 1 \omega 9+11 c$ & $1.9 \pm 0.2$ & $2.9 \pm 0.3$ & $1.3 \pm 0.1$ & $2.2 \pm 0.5$ & $0.9 \pm 0.1$ \\
\hline $20: 1 \omega 7 c$ & $0.4 \pm 0.0$ & $0.6 \pm 0.1$ & $0.4 \pm 0$ & $0.5 \pm 0$ & $0.4 \pm 0.1$ \\
\hline $22: 1 \omega 11 \mathrm{c}$ & $0.7 \pm 0.3$ & $0.4 \pm 0.1$ & $0.3 \pm 0$ & $0.6 \pm 0.2$ & $0.2 \pm 0$ \\
\hline Total & $51.3 \pm 1.1$ & $53.9 \pm 2.7$ & $53.5 \pm 1.8$ & $47.7 \pm 1.8$ & $45.4 \pm 6.8$ \\
\hline \multicolumn{6}{|l|}{ PUFA } \\
\hline $18: 4 \omega 3$ & $0.9 \pm 0.1$ & $0.6 \pm 0.1$ & $0.8 \pm 0.1$ & $0.8 \pm 0.1$ & $0.6 \pm 0.1$ \\
\hline $18: 2 \omega 6$ & $2.5 \pm 0.1$ & $3.0 \pm 0.3$ & $2.5 \pm 0.1$ & $2.4 \pm 0.1$ & $2.1 \pm 0.3$ \\
\hline $18: 3 \omega 3$ & $0.5 \pm 0.0$ & $0.4 \pm 0$ & $0.5 \pm 0$ & $0.5 \pm 0$ & $0.4 \pm 0.1$ \\
\hline $20: 4 \omega 6$ & $0.5 \pm 0.0$ & $0.5 \pm 0$ & $0.5 \pm 0.1$ & $0.6 \pm 0$ & $0.7 \pm 0$ \\
\hline $20: 5 \omega 3$ & $7.9 \pm 0.4$ & $4.8 \pm 0.3$ & $7.6 \pm 0.7$ & $7.5 \pm 0.5$ & $7 \pm 0.5$ \\
\hline $20: 4 \omega 3$ & $0.9 \pm 0.1$ & $0.8 \pm 0.1$ & $1.2 \pm 0.1$ & $1.3 \pm 0.1$ & $1.3 \pm 0.2$ \\
\hline $22: 6 \omega 3$ & $5.6 \pm 0.3$ & $3.8 \pm 0.3$ & $4.8 \pm 0.6$ & $5.8 \pm 0.2$ & $5.5 \pm 0.1$ \\
\hline $22: 5 \omega 3$ & $4.4 \pm 0.3$ & $3.5 \pm 0.2$ & $4.7 \pm 0.5$ & $5 \pm 0.4$ & $5.6 \pm 0.4$ \\
\hline Total & $23.3 \pm 0.9$ & $17.4 \pm 0.9$ & $22.6 \pm 1.9$ & $23.8 \pm 1$ & $23.3 \pm 1.5$ \\
\hline Other $\mathrm{FA}^{\mathrm{b}}$ & $5.8 \pm 0.6$ & $5.8 \pm 0.5$ & $4.6 \pm 0.2$ & $6.5 \pm 0.7$ & $6.8 \pm 2.9$ \\
\hline \multicolumn{6}{|l|}{$a+a 17 \cdot 0$} \\
\hline \multicolumn{6}{|c|}{ 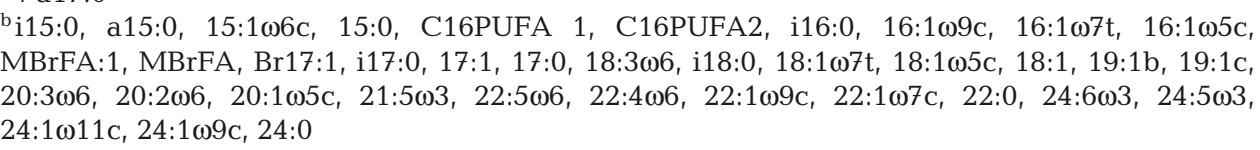 } \\
\hline
\end{tabular}

(1) 'early migration': individuals sampled on the northward leg of the journey, travelling to breeding grounds (sampled June to July); and (2) 'late migration': individuals on the southward leg of the journey, returning to Antarctic feeding grounds (sampled September to October). Animals sampled on the northward leg of the journey are not likely to be the same individual animals sampled on the return journey. All biopsies were obtained with flotation darts fired from a modified 0.22 calibre rifle (Paxarms). The dimensions of biopsy cutting heads were $2.0 \mathrm{~cm}$ length $\times 0.7 \mathrm{~cm}$ diameter. The target region for the biopsies was the whale's dorsum, ventral and caudal to the dorsal fin, as recommended by Lambertsen et al. (1994).
The group composition of biopsied individuals was noted and provides some information regarding the reproductive status of females. Whilst it was not possible to ascertain the reproductive status of early migration females $(n=7)$ due to the absence of accompanying dependent calves, as many as 5 late migration females were identified as lactating mothers due to the presence of accompanying calves-of-theyear. The remaining 3 late migration females were sampled from pods without sighted calves-of-theyear and may be assumed to be either non-pregnant, in the early stages of pregnancy, or mothers that have lost calves-of-the-year. Two female calves-of-theyear were also sampled. In this instance, the mothers were not sampled. Although the profiles of the calves 
in this study appear to resemble those of late migratory female adults, previous studies on humpback whales in the Northern Hemisphere have shown that profiles of individuals $<1$ yr of age differ significantly from individuals $>1$ yr of age (Herman et al. 2009). Consequently, the calves in this study will be treated as a separate group. Data for comparison with Northern Hemisphere humpback whales were sourced from Borobia et al. (1995).

Blubber for lipid and FA analysis was immediately stored on ice and then at $-18^{\circ} \mathrm{C}$. Samples were analysed within 2 mo. Skin subsamples for genetic determination were stored in dimethyl sulfoxide for transportation to the Australian Antarctic Division, Tasmania, for sex determination.

\section{Lipid extraction and class determination}

Pre-weighed (ca. 0.03 g) blubber samples were used for lipid extraction. Individual samples were extracted overnight using a modified Bligh and Dyer (1959) methanol-chloroform-water (MeOH/CHC1 $1_{3}$ / $\mathrm{H}_{2} \mathrm{O}$ ) extraction (2:1:0.8 v/v/v). The following day, chloroform-water was added, yielding a final solvent ratio of 1:1:0.9 v/v/v methanol-chloroform-water. Samples were left to partition into the aqueous and chloroform phases. The lower chloroform phase was collected and reduced by rotary evaporation at $40^{\circ} \mathrm{C}$ to obtain the total lipid extract (TLE). The TLE was concentrated to dryness under a gentle stream of nitrogen gas, and individual samples were re-weighed to determine total lipid content, expressed as percent lipid of the original blubber sample. Samples were re-dissolved in chloroform, and a known aliquot of total lipid (achieving a final concentration of approximately $10 \mathrm{mg}$ lipid $\mathrm{ml}^{-1} \mathrm{CHCl}_{3}$ ) was transferred into separate vials and made up to $1.5 \mathrm{ml}$ of $\mathrm{CHCl}_{3}$. Samples were stored at $-20^{\circ} \mathrm{C}$ until further analysis. Lipid class profiles of all samples were determined by an Iatroscan Mark V TH10 thin layer chromatograph coupled with a flame ionization detector (Volkman \& Nichols 1991).

\section{FA determination}

An aliquot of the TLE was trans-methylated by the addition of $\mathrm{MeOH} / \mathrm{HCl} / \mathrm{CHCl}_{3}$ (3 ml 10:1:1, v/v/v, $80^{\circ} \mathrm{C}, 2 \mathrm{~h}$ ) to produce fatty acid methyl esters (FAME). FAME were extracted $(3 \times)$, after the addition of $1 \mathrm{ml}$ of water, with 4:1 hexane/dichloromethane. A $\mathrm{C}_{19}$ FAME internal injection standard was added prior to analysis by gas chromatography using a gas chromatograph (Agilent Technologies 7890A) equipped with a Supelco Equity ${ }^{\mathrm{TM}}-1$ fused silica capillary column (15 m × $0.1 \mathrm{~mm}$ internal diameter, $0.1 \mu \mathrm{m}$ film thickness; Alhazzaa et al. 2011). GC-MS confirmed FAME identifications and was performed on a Finnigan Thermoquest GCQ gas chromatograph-mass spectrometer fitted with a column of similar polarity to that described above and an on-column injector and using Thermoquest Xcalibur software (Austin). Helium was used as the carrier gas, and other operating conditions were as previously described (Alhazzaa et al. 2011). The relative level of individual FA was expressed as percent of total FA area. FA present in trace amounts $(<0.5 \%)$ were excluded from the presented results and are grouped as other FA and listed in Table 1.

\section{Quality control and statistical analyses}

For lipid class and FA profiling, commercial (Nucheck) and laboratory standards (e.g. tuna oil) of known composition were routinely analysed with blubber samples to both confirm component identifications and ensure data quality.

Data were determined to be normally distributed using a Kolmogorov-Smirnov test. Principal component analysis (PCA) was used for exploration of differences between FA profiles of Northern Hemisphere and Southern Hemisphere humpback whale populations and also to make inferences about Southern Hemisphere humpback whale prey species. Each sample was positioned in the multi-dimensional space described by the variables (FA). New coordinates (principal components, PC) through the centroid of the samples and orthogonal to each other, in the direction of the largest and second-largest variance among the samples, were computed. In this manner, the relationship between the samples was described in 2 dimensions, retaining the systematic variation among the samples. The relative positions of the samples were displayed by projecting them on a plane defined by 2 new co-ordinates, i.e. PC1 and PC2. In these plots, the correlations among samples and FA are also shown as a loading plot. FA with high positive or negative values along a PC have high importance for that PC and, consequently, for the position of the samples in the plot. Discriminant function analysis (DFA) was employed to predict whether individual humpback whales could be grouped according to sex or migration status by their FA profiles. Predictor variables included all 20 FA 
$(>0.5 \%)$, and analysis of the structure matrix was utilised to determine which individual FA were the highest significant predictors for assigning each animal into the aforementioned groups. A 1-way ANOVA $(p \leq 0.05)$ quantitatively assessed the significance of the differences among the proportions of individual and groups of FA in the different cohorts. Statistics were conducted using IBM SPSS (version 20 , SPSS). Results are presented as means \pm SE.

\section{RESULTS AND DISCUSSION}

\section{Lipid composition}

The depot lipids in east Australian humpback whales were found to be primarily stored as TAG, constituting almost $100 \%(97.6 \pm 0.5 \%, \mathrm{n}=54)$ by weight of lipid. This blubber lipid class composition is similar to that reported for other marine mammal species (Raclot 2003, Budge et al. 2006, Iverson 2008).

The expected energy depletion over the course of the migration event was evidenced by a statistically significant decrease in blubber lipid content from biopsied early migration males $(43.3 \pm 2.5 \%, \mathrm{n}=17)$ compared to biopsied late migration males $(32 \pm 5 \%$, $\mathrm{n}=12 ;$ Fig. 1$)$ as determined by 1 -way ANOVA $\left(F_{1,27}\right.$ $=6.4, \mathrm{p}=0.01)$. Although the same trend was apparent in biopsied females (early migration $46.7 \pm 2.7 \%$, $\mathrm{n}=6$; late migration $46.1 \pm 4.8 \%, \mathrm{n}=8$; Fig. 1 ), the

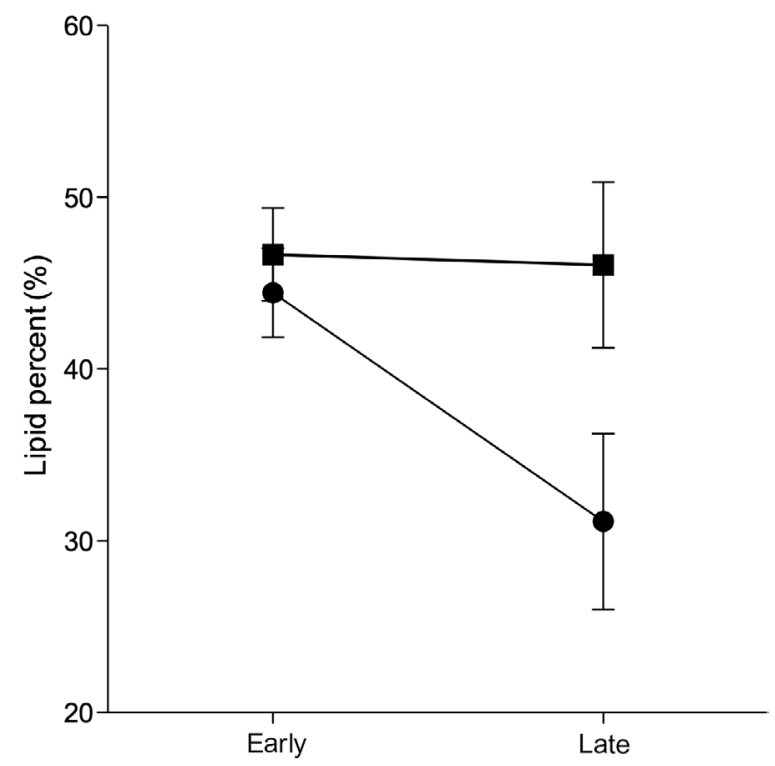

Fig. 1. Megaptera novaeangliae. Difference in Southern Hemisphere humpback whale blubber lipid content of the outer blubber layer between early and late migration of males (৩) and females ( differences were not statistically significant and were likely impacted by both the smaller sample sizes and large variances which may be caused by compounding factors of gestation and lactation.

\section{FA profiles}

Twenty individual FA were identified in greater than trace levels $(\geq 0.5 \%)$ in sampled animals $(\mathrm{n}=54$; Table 1). The 5 dominant FA detected in decreasing order of importance were $18: 1 \omega 9 \mathrm{c}, 16: 1 \omega 7 \mathrm{c}, 16: 0$, 18:1 $\omega 7 \mathrm{c}$, and 20:5 $\omega 3$ (eicosapentaenoic acid, EPA). Of the 3 FA groups (saturated fatty acids, SFA; monounsaturated fatty acids, MUFA; and polyunsaturated fatty acids, PUFA), MUFA dominated all male (early migration $=51.9 \pm 0.9 \%$, late migration $=52.8$ $\pm 1.8 \%$ ), female (early migration $=53.5 \pm 1.8 \%$, late migration $=47.7 \pm 1.8 \%)$, and calf $(45.4 \pm 6.8 \%) \mathrm{FA}$ profiles (Table 1). The 5 dominant FA occurring in calf profiles $(\mathrm{n}=2$; Table 1$)$ were identical to adult profiles, likely reflecting their dependence on their mother's lipid stores.

\section{Migration}

DFA of all 20 FA revealed a significant difference between early and late migration male humpback whales, with $94.4 \%$ of individuals being correctly classified according to FA profiles (Fig. 2A). FA that were the most significant predictors responsible were 20:0 and 20:5 03 . Further, ANOVA investigations showed that the contribution of long-chain PUFA (LC-PUFA, $\geq 20$ carbons) to the FA profile of males showed a significant decrease from early to late migration time points (early: $19.4 \pm 3.4 \%$, migration: $14.9 \pm 3.4 \% ; F_{1,34}=15.6, \mathrm{p}<0.001$; Fig. 3A). When assessed on an individual FA basis, the PUFA 18:4 $\omega 3$ and EPA were significantly diminished in late migration males compared to early migration counterparts $\left(18: 4 \omega 3,1\right.$-way ANOVA, $F_{1,37}=4.3, \mathrm{p}<0.05$; EPA, 1-way ANOVA, $F_{1,37}=5.2, p<0.05$ ). These findings indicate that male humpback whales favour PUFA utilisation to sustain their energy requirements throughout the annual migration and fasting event. Mobilisation of certain FA is deemed a sequential and even a selective (e.g. hormonally controlled) process in mammalian adipose tissue (Raclot 2003, Nieminen et al. 2006, Wheatley et al. 2008). The physicochemical properties of FA, as determined by their chemical structures, have been found to play a significant role in mobilisation during a period of 

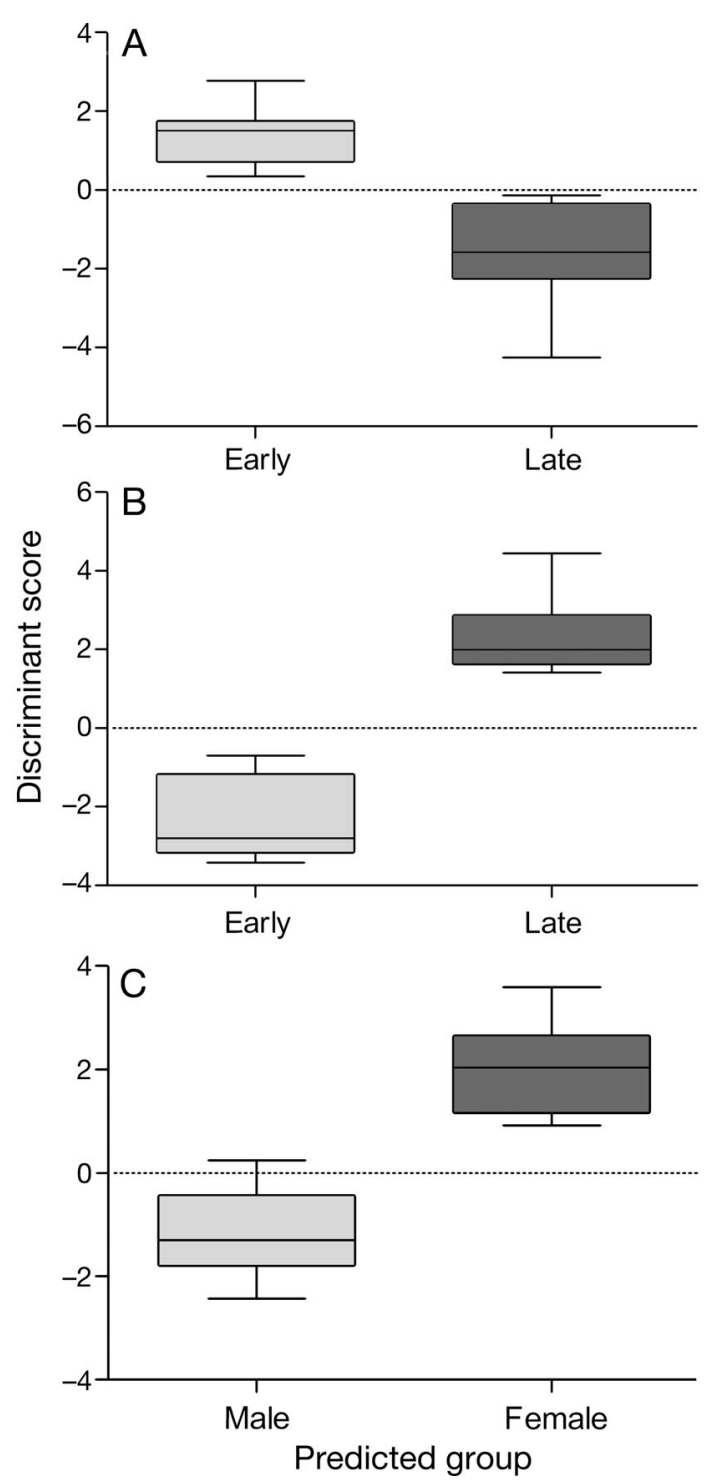

Fig. 2. Megaptera novaeangliae. Box plots illustrating the distribution of discriminant scores for the blubber fatty acid profiles of 2 groups, males and females. Minimal or no overlap of the box plots reveals a substantial differentiation and shows that the function discriminates well. The box is divided at the median value. The whisker is drawn from the top of the box to the largest value, and the same on the bottom. (A) Males discriminated by migration status, early $(\mathrm{n}=$ 17), late $(\mathrm{n}=12)$; (B) females discriminated by migration status, early $(n=7)$, late $(n=8)$; $(C)$ late migration cohorts discriminated by gender, male $(n=12)$, female $(n=8)$

fasting (Raclot 2003). FA with 16 to 20 carbons and 4 to 5 double bonds (i.e. PUFA) appear to be the most readily mobilised in rats and humans (Raclot \& Groscolas 1995, Raclot et al. 1997, Raclot 2003). Within this FA classification, a shorter carbon chain, more double bonds, and the closer the first double bond is to the methyl end of the FA further enhanced

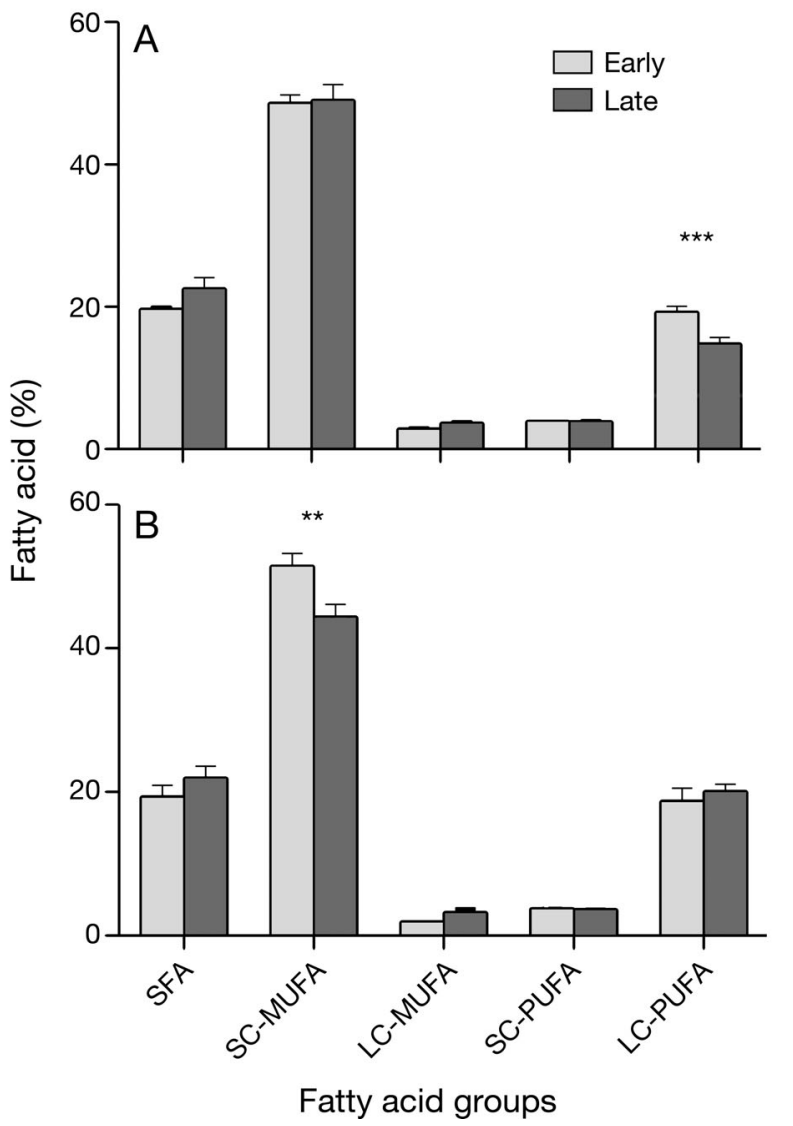

Fig. 3. Megaptera novaeangliae. Fatty acid profiles of early and late migration east Australian (A) male and (B) female humpback whales. ${ }^{* *} \mathrm{p}<0.01 ;{ }^{* * *} \mathrm{p}<0.001$. SFA, saturated fatty acids; SC-MUFA, short-chain monounsaturated fatty acids; LC-MUFA, long-chain monounsaturated fatty acids; SC-PUFA, short-chain polyunsaturated fatty acids; LCPUFA, long-chain polyunsaturated fatty acids

mobilisation (Raclot et al. 1995). In the current study, PUFA mobilisation in male animals during migration appears to occur in accordance with these physicochemical properties. PUFA-derived energy may provide a competitive advantage for males engaging in energetically demanding breeding behaviour over the course of the migration and fasting event.

Females from the study population differ from their male counterparts in that they appear to favour shortchain MUFA (SC-MUFA, $\leq 18$ carbons) mobilisation throughout the migration event. DFA revealed significant differentiation by correctly classifying female humpback whales into migration groups by FA profiles $100 \%$ of the time (Fig. 2B). The strongest significant predictors of groups belonged to the MUFA

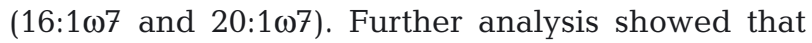
SC-MUFA significantly decreased in contribution 
from early to late migration (early: $51.5 \pm 1.8$; late: $44.5 \pm 1.8$ ), with no change according to migration status in any other FA groups (Fig. 3B). When MUFA were assessed individually, both of the decreasing MUFA were shown to be SC-MUFA (1-way ANOVA; $14: 1 \omega 5, F_{1,15}=6.9, \mathrm{p}=0.01 ; 16: 1 \omega 7 \mathrm{c}, F_{1,15}=17.6, \mathrm{p}=$ $0.001)$.

\section{Gender}

Gender FA profile differences are not discernible at the early stages of migration, with male and female profiles being indistinguishable (Fig. 4A). However, by late migration, there are clear differences between the 2 gender profiles (Fig. 4B). These emerging differences between genders are likely attributed to the changing reproductive status of females (Iverson et al. 1995, Grahl-Nielsen et al. 2000). During lactation, individual FA may not only be mobilised according to their molecular structure, as described above (Raclot 2003), but may also be mobilised according to the physiological requirements of mother and offspring (Samuel \& Worthy 2004). In the current study, the differences between the 2 genders in late migration cohorts were primarily reflected by a significantly greater proportion of LC-PUFA retained by females compared to their male counterparts (late migration males $=14.9 \pm 0.9 \%$, late migration females $=20.1 \pm$ $1 \%$; 1 -way ANOVA, $F_{1,23}=14.8, \mathrm{p}=0.001$; Fig. 4B). When LC-PUFA were individually assessed between late migration gender groups, the contributions of each individual LC-PUFA was significantly greater in females compared to males $\left(20: 4 \omega 6, F_{1,23}=4.6\right.$, $\mathrm{p}<0.05 ; 20: 5 \omega 3, F_{1,23}=12, \mathrm{p}<0.01 ; 20: 4 \omega 3, F_{1,23}=$ $8.2, \mathrm{p}<0.01 ; 22: 6 \omega 3, F_{1,23}=8.7, \mathrm{p}<0.01 ; 22: 5 \omega 3$, $F_{1,23}=7.5, \mathrm{p}=0.01$; Table 3 ). DFA supported these results, with $92 \%$ of individuals being correctly clas-

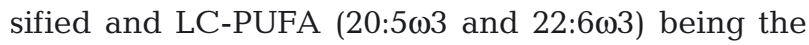
most significant predictors (Fig. 2C).

Given the importance of these essential PUFA for the development of healthy offspring, it is feasible that females are retaining certain LC-PUFA for mobilisation at essential development time points. This type of staggered mobilisation of individual essential PUFA has previously been evidenced in female Weddell seals Leptonychotes weddellii (Wheatley et al. 2008). For the Weddell seal, 20:5 03 was more readily mobilised early in lactation, with

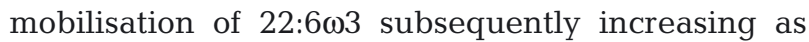
20:5 $\omega 3$ decreased. This pattern was attributed to the physiological requirements of the offspring (Innis 2005, Wheatley et al. 2008).
Coinciding with the retention of PUFA is the aforementioned decrease of SC-MUFA in late migration females. In the current study, more than half $(n=5)$ of the late migration females sampled were identified as lactating mothers due to the presence of a dependent calf. The reproductive status of the remaining ( $\mathrm{n}$ = 3) late migration adult females was unknown, and they must be assumed to be either non-pregnant, in the early stages of pregnancy, or mothers that have lost calves-of-the-year. The lipid profiles of these 3 individuals, however, closely resembled those of lactating mothers and showed a similar diminishing of SC-MUFA stores, favouring the possibility that they were at similar reproductive stages (Samuel \& Worthy 2004).

It has been suggested that different groups of FA are mobilised at 3 distinct time points during marine mammal lactation, i.e. postpartum, mid-lactation,

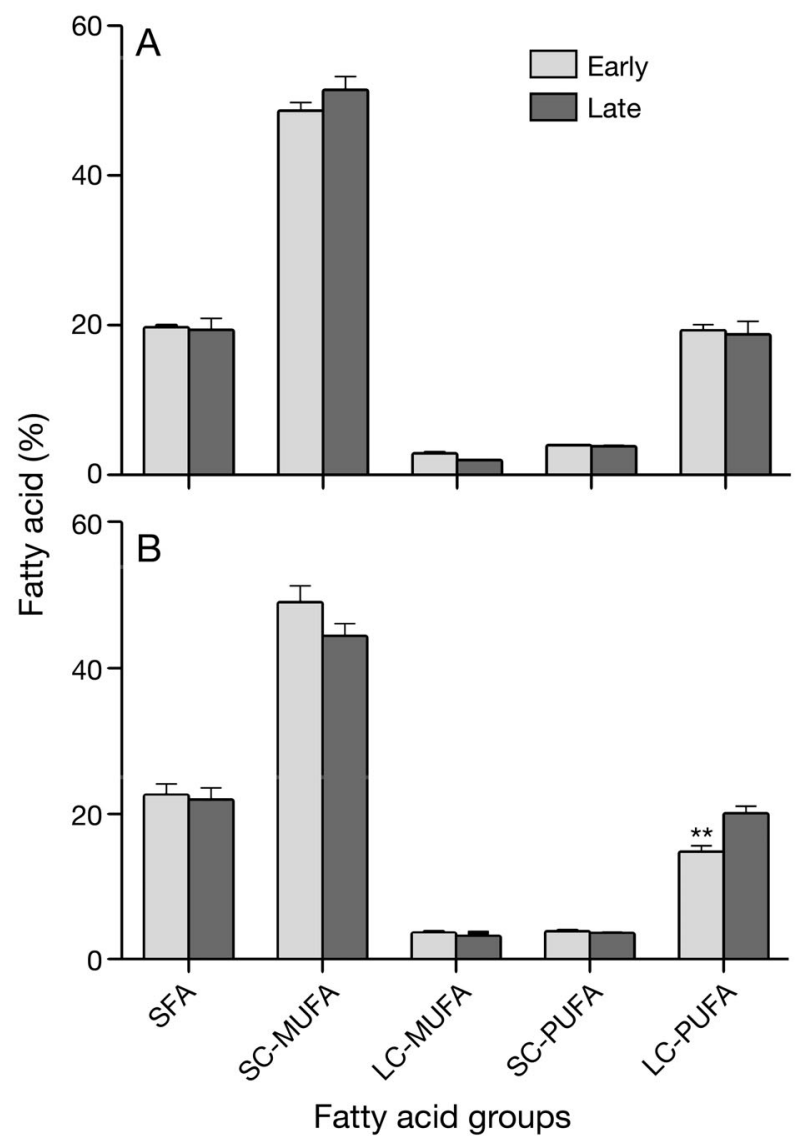

Fig. 4. Megaptera novaeangliae. Fatty acid profiles of (A) early migration and (B) late migration humpback whales. ${ }^{* * *} \mathrm{p}<0.001$. SFA, saturated fatty acids; SC-MUFA, shortchain monounsaturated fatty acids; LC-MUFA, long-chain monounsaturated fatty acids; SC-PUFA, short-chain polyunsaturated fatty acids; LC-PUFA, long-chain polyunsaturated fatty acids 
and end of lactation (Wheatley et al. 2008). Large baleen whales generally have a lactation period of 5 to 7 mo (Oftedal 2000), which in humpback whales can sometimes extend to more than 12 mo (Clapham 2000). Thus, at the time of sampling (i.e. at the beginning of the southward migration), we can assume that the lactation time point is between postpartum and mid-lactation. The decrease in SC-MUFA in the mother's blubber stores would therefore indicate an increase of SC-MUFA in milk for the calf. Such an increase in MUFA in the milk of Weddell seals between postpartum and mid-lactation has been shown, with essential LC-PUFA being mobilised later in lactation (Wheatley et al. 2008). It was further concluded that lactating mothers might initially prioritise resources for the offspring's thermoregulatory needs, with essential proteins for development being mobilised later in lactation (Wheatley et al. 2008). Maintaining blubber fluidity for thermoregulation is a priority for cetaceans that inhabit cold, highlatitude waters. Species that inhabit cold waters have physiologically adapted to their environment by decreasing the chain length of FA (i.e. lowering the melting point) in the outer blubber layer and, thus, maintaining blubber fluidity to improve insulation and meet energy requirements (Gurr \& Harwood 1991, Fredheim et al. 1995, Samuel \& Worthy 2004). The decrease of SC-MUFA shown in lactating female humpback whales at postpartum to mid-lactation may then be explained by initial prioritisation of the calf's thermoregulatory requirements in preparation for return to cold Southern Ocean waters. Similarly, the retained essential PUFA may be mobilised at later critical time points of growth and development of the calf. The FA mobilisation process in females is thus likely governed by complex hormonal controls brought on by physiological changes imposed on animals during reproduction (Samuel \& Worthy 2004).

Although no cow and calf pairs were targeted in this study, calf blubber FA profiles ( $\mathrm{n}=2$, Table 1) closely reflect those of late migration females, reflecting the milk-derived energy stores of the calves. However, this is not always the case in marine mammals; for example, significant differences were found between the blubber FA profiles of Weddell seal mothers and their pups (Wheatley et al. 2008) and between the profiles of Northern Hemisphere humpback whales $<1 \mathrm{yr}$ of age when compared to humpback whales $>1$ yr of age (Herman et al. 2009). Although this similarity between calves and female adults is notable, the small sample size precludes further discussion.

\section{Feeding ecology}

PCA displayed the relationship between Southern Hemisphere humpback whales and their prey species, Antarctic krill Euphausia superba (Phleger et al. 1998, Phleger et al. 2002, Stubing \& Hagen 2003, O'Brien et al. 2011), alongside a population of humpback whales from the Northern Hemisphere that have a markedly different foraging ecology (data from Borobia et al. 1995). Because there was a difference in the selection of FA between investigators, 10 abundant FA determined in all the studies were used in these comparisons. The resulting plot revealed clear distinctions between humpback whale blubber and the prey species, with a clear distinction also observed between the 2 populations of humpback whales with differing foraging ecology (Fig. 5A). The first principal component (PC1) accounted for $46 \%$ of the variance, the majority of which was caused by LC-PUFA, and the second principal component (PC2) accounted for another $24 \%$ of the variance and was most strongly affected by long-chain MUFA; cumulatively, the 2 co-ordinates accounted for $70 \%$ of the variance (Fig. 5B). This distinction of FA compositions in species with large differences in foraging ecology, and that of predator and prey, indicates the influence of both diet and species-specific metabolism on FA composition. Separation of Southern Hemisphere humpback whale profiles from those of their dominant prey item indicates metabolic modification of the FA composition from ingestion to deposition. This corresponds with previous studies on marine mammals that suggest that the FA composition of blubber never exactly matches that of the diet (Best et al. 2003, Iverson et al. 2004, GrahlNielsen et al. 2011) and is modified according to species-specific metabolic demands. Even if metabolism is an important force, however, there is still evidence to suggest that prey has an impact on FA composition, as shown by the separation of the 2 distinct populations of humpback whales. The FA trophic marker concept may be applied to distinguish dietary preference (Dalsgaard et al. 2003).

To further investigate the ecological niche of Southern Hemisphere humpback whales, their trophic level was investigated by utilising FA ratios to determine dietary preference between the 2 euphausiid species Euphausia superba and Nyctiphanes australis. E. superba is both widely distributed in and restricted to the Southern Ocean. N. australis was chosen as a comparison, as it occurs in more temperate waters than E. superba and there are anecdotal 

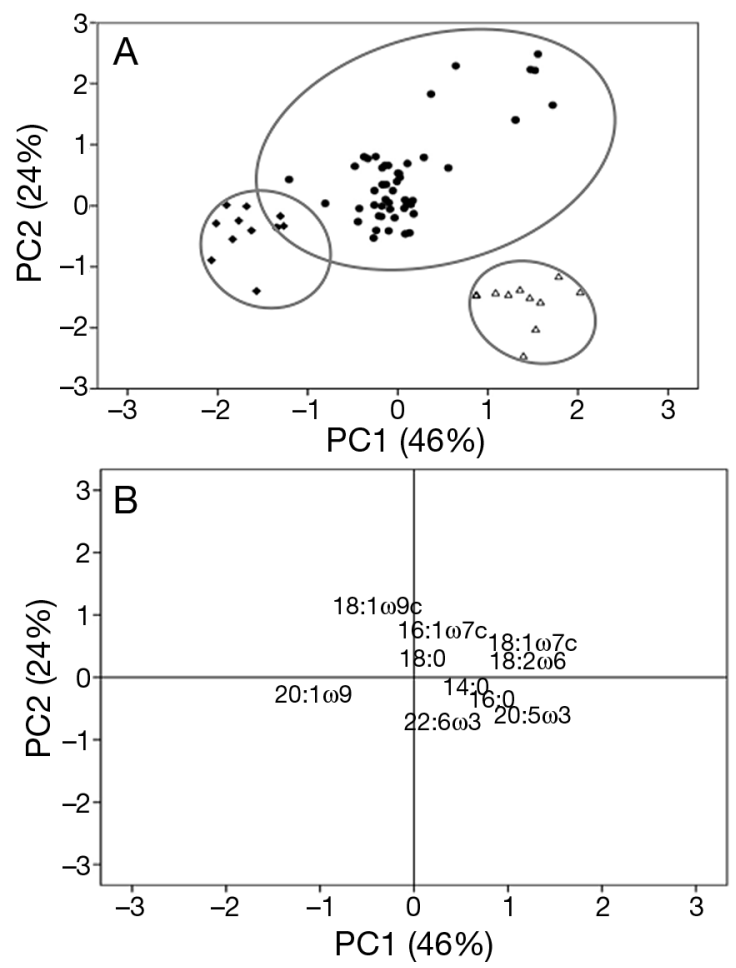

Fig. 5. Megaptera novaeangliae. (A) Principal component analysis of fatty acid (FA) profiles of Southern Hemisphere humpback whales (closed circles; this study), Northern Hemisphere humpback whales (closed diamonds; Borobia et al. 1995), and Antarctic krill Euphausia superba (open triangle; Phleger et al. 1998, 2002, Stubing \& Hagen 2003, O'Brien et al. 2011). The first 2 principal components (PC1, PC2) combined explained $70 \%$ of the variance. (B) Loading plot of the importance of an individual FA in determining between the outer and inner blubber layer. The farther away from the origin that an FA is located in the plot, horizontally or vertically, the more important it is for the direction of the first and second components, respectively. A sample located close to an FA contains a higher relative amount of that FA than the more remotely located samples

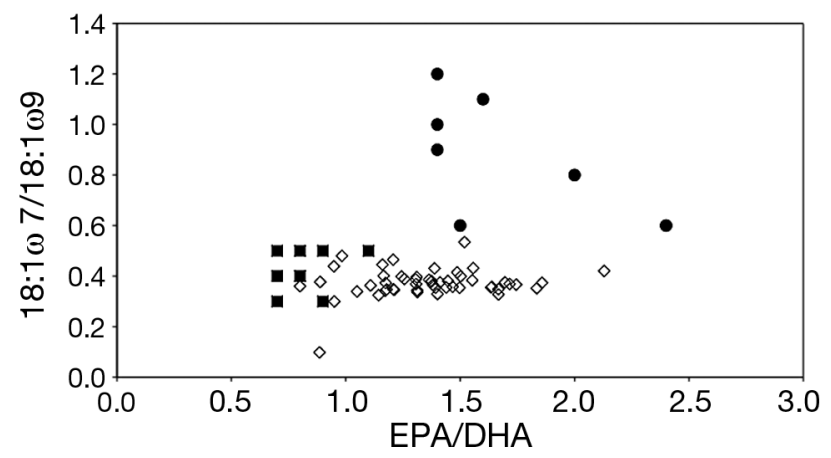

Fig. 6. Megaptera novaeangliae. Vaccenic acid/oleic acid and eicosapentaenoic acid (EPA)/docosahexaenoic acid (DHA) ratios of the east Australian population of humpback whales (open diamonds; this study), Antarctic krill Euphausia superba (closed circles; Phleger et al. 1998, 2002, Stubing \& Hagen 2003, O'Brien et al. 2011) and temperate krill, Nyctiphanes australis (closed squares; Virtue et al. 2005) reports of mid-migration feeding by the humpback whale on this species along the east Australian coastline (Gill et al. 1998, Virtue et al. 1995). FA ratios have been used in previous food web studies and show that a high 18:1 $\omega 7 \mathrm{c} / 18: 1 \omega 9 \mathrm{c}$ (vaccenic acid/ oleic acid) ratio is consistent with a herbivorous diet and a high 20:5 $\omega 3 / 22: 6 \omega 3$ (EPA/docosahexaenoic acid, DHA) ratio reflects a diatom diet, whereas low EPA/DHA ratios reflect a flagellate diet (Phleger et al. 2002, Stubing \& Hagen 2003, Stubing et al. 2003). Here, the low vaccenic acid/oleic acid ratio of humpback whales and $N$. australis indicates that they both occupy a more carnivorous niche than E. superba. The similar trophic level of humpback whales and $N$. australis provides evidence against a predator-prey relationship (Fig. 6). Thus, the high EPA/DHA ratio shared by both the humpback whales and E. superba indicated that they both derive energy from a diet of diatom origin, whereas the lower ratio found in $N$. australis indicates a more flagellate-based diet (Fig. 6). These data lend support for the ecological niche of Southern Hemisphere humpback whales as highfidelity Antarctic krill feeders.

\section{CONCLUSIONS}

This study provides the first description of lipid and FA profiles of Southern Hemisphere humpback whales. Gender and migration cohort comparisons provide evidence for selective utilisation and retention of individual FA, and FA groups, during a key time of energy deficit. Females appear to prioritise calves' thermoregulatory needs by initially offloading SC-MUFA during early lactation while managing to retain a greater proportion of LC-PUFA, potentially for mobilisation at critical time points of growth and development. By contrast, FA mobilisation in migrating males adhered to the pattern expected from the physicochemical properties of individual FA. Feeding ecology investigations suggested that humpback whales have a species-specific FA composition of their blubber with a detectable influence of the diet. FA ratio analysis provided further evidence in support of the ecological niche of Southern Hemisphere humpback whales as high-fidelity Antarctic krill E. superba feeders. A comprehensive understanding of FA dynamics is not only important for expanding our knowledge of trophic interactions and foraging behaviour of the species but is essential for evaluation of nutritional status and thereby also the risks posed by lipophilic pollutants, particularly at times of energy deficit. 
Acknowledgements. The authors thank M. Double (AAD) for performing DNA sex determination of the animals utilised in this study, P. Mansour for assistance with lipid/FA methods, and D. Holdsworth for help with management of the CSIRO GC-MS facility. Field volunteers are acknowledged for their contribution to sample collection. Entox is a partnership between the University of Queensland and Queensland Health Scientific Services.

\section{LITERATURE CITED}

Alhazzaa R, Bridle AR, Nichols PD, Carter CG (2011) Upregulated desaturase and elongase gene expression promoted accumulation of polyunsaturated fatty acid (PUFA) but not long-chain PUFA in Lates calcarifer, a tropical euryhaline fish fed a stearidonic- and $\gamma$-linoleic acid enriched diet. J Agric Food Chem 59:8423-8434

Bannister JL, Hedley S (2001) Southern Hemisphere Group IV humpback whales: their status from recent aerial survey. Mem Queensl Mus 47:587-598

> Baraff LS, Clapham PJ, Mattila DK, Bowman RS (1991) Feeding behaviour of a humpback whale in low-latitude waters. Mar Mamm Sci 7:197-202

Best NJ, Bradshaw CJA, Hindell MA, Nichols PD (2003) Vertical stratification of fatty acids in the blubber of southern elephant seals (Mirounga leonina): implications for diet analysis. Comp Biochem Physiol B 134:253-263

Bigsby RM, Caperell-Grant A, Madhukar BV (1997) Xenobiotics released from fat during fasting produce estrogenic effects in ovariectomized mice. Cancer Res 57:865-869

Bligh EG, Dyer WJ (1959) A rapid method of total lipid extraction and purification. Can J Biochem Physiol 37: 911-917

Borobia M, Gearing PJ, Simard Y, Gearing JN, Beland P (1995) Blubber fatty acids of finback and humpback whales from the Gulf of Saint Lawrence. Mar Biol 122: 341-353

Budge SM, Iverson SJ, Koopman HN (2006) Studying trophic ecology in marine ecosystems using fatty acids: a primer on analysis and interpretation. Mar Mamm Sci 22: 759-801

Budge SM, Springer AM, Iverson SJ, Sheffield G, Rosa C (2008) Blubber fatty acid composition of bowhead whales Balena mysticetus: implications for diet assessment and ecosystem monitoring. J Exp Mar Biol Ecol 359:40-46

Chittleborough RG (1965) Dynamics of two populations of humpback whale, Megaptera nodosa (Bonnaterie). Aust J Mar Freshw Res 16:33-128

Clapham PJ (2000) The humpback whale. In: Mann JC, Connor RC, Tyack PL, Whitehead H (eds) Cetacean societies. University of Chicago Press, Chicago, IL, p 173-196

Costa DP (2008) Energetics. In: Perrin WF, Wursig B, Thewissen JGM (eds) The encyclopaedia of marine mammals. Academic Press, San Diego, CA, p 791-796

> Dalsgaard J, St John M, Kattner G, Muller-Navarra D, Hagen W (2003) Fatty acid trophic markers in the pelagic marine environment. Adv Mar Biol 46:225-340

Dawbin WH (1966) The seasonal migratory cycle of humpback whales. In: Norris KS (ed) Whales, dolphins, and porpoises. University of California Press, Berkeley, CA, p 145-170

Fredheim B, Holen S, Ugland KI, Grahl-Nielsen O (1995) Fatty acid composition in blubber, heart and brain from phocid seals. In: Blix AS, Walløe L, Ulltang $\varnothing$ (eds)
Whales, seals, fish and man. Elsevier Science BV, Amsterdam, p 153-168

Gill PC, Evans KJ, Wapstra H (1998) Feeding by humpback whales in Tasmanian waters. Rec Queen Vic Mus 107: $1-5$

Grahl-Nielsen O, Hammill MO, Lydersen C, Wahlstrom S (2000) Transfer of fatty acids from female seal blubber via milk to pup blubber. J Comp Physiol B 170:277-283

> Grahl-Nielsen O, Haug T, Lindstrøm U, Nilssen KT (2011) Fatty acids in harp seal blubber do not necessarily reflect their diet. Mar Ecol Prog Ser 426:263-276

Gurr MI, Harwood JL (1991) Lipid biochemistry: an introduction. Chapman and Hall, New York, NY

Herman DP, Matkin CO, Ylitalo GM, Durban JW and others (2008) Assessing age distributions of killer whale Orcinus orca populations from the composition of endogenous fatty acids in their outer blubber layers. Mar Ecol Prog Ser 372:289-302

Herman DP, Ylitalo GM, Robbins J, Straley JM and others (2009) Age determination of humpback whales Megaptera novaeangliae through blubber fatty acid compositions of biopsy samples. Mar Ecol Prog Ser 392:277-293

> Imbeault P, Chevrier J, Dewailly E, Ayotte P, Despres JP, Tremblay A, Mauriege P (2001) Increase in plasma pollutant levels in response to weight loss in humans is related to in vitro subcutaneous adipocyte basal lipolysis. Int $\mathrm{J}$ Obes 25:1585-1591

Innis SM (2005) Essential fatty acid metabolism during early development. In: Burrin DG, Mersmann HJ (eds) Biology of metabolism in growing animals. Elsevier, Sydney

International Whaling Commission (1999) Report of the scientific committee. Annex E. Report of the sub-committee on other great whales. J Cetacean Res Manag 1(Suppl): $117-155$

Iverson SJ (2008) Blubber. In: Perrin WF, Wursig B, Thewissen JGM (eds) The encyclopaedia of marine mammals. Academic Press, San Diego, CA, p 107-111

> Iverson SJ, Hamosh M, Bowen WD (1995) Lipoprotein lipase activity and its relationship to high milk fat transfer during lactation in grey seals. J Comp Physiol B 165:384-395

> Iverson SJ, Frost KJ, Lang SLC (2002) Fat content and fatty acid composition of forage fish and invertebrates in Prince William Sound, Alaska: factors contributing to among and within species variability. Mar Ecol Prog Ser 241:161-181

> Iverson SJ, Field C, Bowen WD, Blanchard W (2004) Quantitative fatty acid signature analysis: a new method of estimating predator diets. Ecol Monogr 74:211-235

Kakela R, Hyvarinen H (1996) Site-specific fatty acid composition in adipose tissues of several northern aquatic and terrestrial mammals. Comp Biochem Physiol B 115: 501-514

Lambertsen RH, Baker CS, Weinrich M, Modi WS (1994) An improved whale biopsy system designed for multidisciplinary research. In: Fossi MC (ed) Nondestructive biomarkers in vertebrates. Lewis Publishers, Boca Raton, FL, p 219-244

Lockyer C (1981) Growth and energy budgets of large baleen whales from the Southern Hemisphere. In: Mammals in the seas, Vol 3: general papers and large cetaceans. FAO Fish Ser No 5, Rome, p 379-488

Martineau D, Lemberger K, Dallaire A, Labelle P, Lipscomb TP, Michel P, Mikaelian I (2002) Cancer in wildlife, a case study: beluga from the Saint Lawrence Estuary, Quebec, Canada. Environ Health Perspect 110:285-292 
Nemoto T (1959) Food of baleen whales with reference to whale movements. Sci Rep Whales Res Inst 14:149-290

Nieminen P, Kakela R, Pyykonen T, Mustonen AM (2006) Selective fatty acid mobilization in the American mink (Mustela vison) during food deprivation. Comp Biochem Physiol B 145:81-93

O'Brien C, Virtue P, Kawaguchi S, Nichols PD (2011) Aspects of krill growth and condition during late winterearly spring off east Antarctica $\left(110-130^{\circ} \mathrm{E}\right)$. Deep-Sea Res II 58:1211-1221

Oftedal OT (2000) Use of maternal reserves as a lactation strategy in large mammals. Proc Nutr Soc 59:99-106

Paterson R, Paterson P, Cato D (2001) Status of humpback whales, Megaptera novaeangliae, in east Australia at the end of the 20th century. Mem Queensl Mus 47:579-580

Phleger CF, Nichols PD, Virtue P (1998) Lipids and trophodynamics of Antarctic zooplankton. Comp Biochem Physiol B 120:311-323

Phleger CF, Nelson MM, Mooney BD, Nichols PD (2002) Interannual and between species comparison of the lipids, fatty acids and sterols of Antarctic krill from the US AMLR Elephant Island survey area. Comp Biochem Physiol B 131:733-747

Raclot T (2003) Selective mobilization of fatty acids from adipose tissue triacylglycerols. Prog Lipid Res 42:257-288

Raclot T, Groscolas R (1995) Selective mobilization of adipose tissue fatty acids during energy depletion in the rat. J Lipid Res 36:2164-2173

Raclot T, Mioskowski E, Bach AC, Groscolas R (1995) Selectivity of fatty acid mobilization: a general metabolic feature of adipose tissue. Am J Physiol 269:R1060-R1067

Raclot T, Langin D, Lafontan M, Groscolas R (1997) Selective release of human adipocyte fatty acids according to molecular structure. Biochem J 324:911-915

Rasmussen K, Palacios DM, Calambokidis J, Sabor MT and 5 others (2007) Southern Hemisphere humpback whales wintering off Central America: insights from water temperature into the longest mammalian migration. Biol Lett 3:302-305

Samuel AM, Worthy GAJ (2004) Variability in fatty acid composition of bottlenose dolphin (Tursiops truncates) blubber as a function of body site, season, and reproductive state. Can J Zool 82:1933-1942

Slijper EJ (1962) Whales. Hutchinson, London

Stevick PT, Neves MC, Johansen F, Engel MH, Allen J, Marcondes MCC, Carlson C (2011) A quarter of a world away: female humpback whale moves $10000 \mathrm{~km}$ between breeding areas. Biol Lett 7:299-302

Strandberg U, Kakela A, Lydersen C, Kovacs KM, Grahl-

Editorial responsibility: Peter Corkeron,

Woods Hole, Massachusetts, USA
Neilsen O, Hyvarinen H, Kakela R (2008) Stratification, composition, and function of marine mammal blubber: the ecology of fatty acids in marine mammals. Physiol Biochem Zool 81:473-485

> Strandberg U, Sipila T, Koskela J, Kunnasranta M, Kakela R (2011) Vertical fatty acid profiles in blubber of a freshwater ringed seal - comparison to a marine relative. J Exp Mar Biol Ecol 407:256-265

Stubing D, Hagen W (2003) Fatty acid biomarker ratios Suitable trophic indicators in Antarctic euphausiids? Polar Biol 26:774-782

Stubing D, Hagen W, Schmidt K (2003) On the use of lipid biomarkers in marine food web analyses: an experimental case study on the Antarctic krill, Euphausia superba. Limnol Ocean 48:1685-1700

Thiemann GW, Iverson SJ, Stirling I (2009) Using fatty acids to study marine mammal foraging: the evidence from an extensive and growing literature. Mar Mamm Sci 25: 243-249

Tollit DJ, Pierce GJ, Hobson KA, Bowen WD, Iverson SJ (2010) Diet. In: Boyd IL, Don Bowen W, Iverson SJ (eds) Marine mammal ecology and conservation: a handbook of techniques. Oxford University Press, Oxford, p 191-221

Virtue P, Johannes RE, Nichols PD, Young JW (1995) Biochemical composition of Nyctiphanes australis and its possible use as an aquaculture feed source: lipids, pigments and fluoride content. Mar Biol 122:121-128

Volkman JK, Nichols PD (1991) Applications of thin layer chromatography-flame ionization detection to the analysis of lipids and pollutants in marine environmental samples. J Planar Chromatogr Mod TLC 4:19-26

Wheatley KE, Nichols P, Hindell MA, Harcourt RG, Bradshaw CJA (2008) Differential mobilisation of blubber fatty acids in lactating Weddell seals: evidence for selective use. Physiol Biochem Zool 81:651-662

Witteveen $\mathrm{BH}$, Worthy GAJ, Wynee KM, Hirons AC, Andrews AG, Markel RW (2011) Trophic levels of North Pacific humpback whales (Megaptera novaeangliae) through analysis of stable isotopes: implications on prey and resource quality. Aquat Mamm 37:101-110

Yordy JE, Wells RS, Balmer BC, Schwacke LH, Rowles TK, Kucklick JR (2010) Partitioning of persistent organic pollutants between blubber and blood of wild bottlenose dolphins: implications for biomonitoring and health. Environ Sci Technol 44:4789-4795

Zerbini AN, Andriolo A, Heide-Jorgensen MP, Pizzorno JL and 6 others (2006) Satellite-monitored movements of humpback whales Megaptera novaeangliae in the Southwest Atlantic Ocean. Mar Ecol Prog Ser 313:295-304

Submitted: March 19, 2012; Accepted: September 17, 2012

Proofs received from author(s): November 29, 2012 